show how far they were neurologically perfect. My personal experience thus differs sharply from that of Kennedy, who found that neurolysis yielded slightly less good results than nerve section and suture. I have only one reservation to make: after the removal of pressure by cervical ribs it is most rare for atrophy of muscles to be entirely repaired; this I am inclined to attribute to the fact that a chronic neuritis has followed the original pressure lesion, and that such neuritis leaves indelible changes which are rarely found in traumatic cases of pure compression.

I have not painted the picture in rosy colours; the greatest optimism is generally that of the man who records a few remarkable cases-often a single case. After many years I can only say that if a surgeon obtains 50 per cent. of really good economic recoveries after secondary nerve suture he is doing well; if he obtains 75 per cent. of such recoveries, which will bear investigation, his work is both brilliant and fortunate.

\section{PROGNOSIS IN CERTAIN AFFECTIONS OF THE HEART.}

BY.W. T. RITCHIE, O.B.E., M.D., F.R.C.P.E., PHYSICIAN TO THE DEACONESS HOSPITAL, AND ASSISTANT PHYSICIAN TO THE ROYAL INFIRMARY, EDINBURGH.

To those who are suffering from affections of the heart prognosis is of the, utmost importance. The parents of the boy whose heart was strained ask whether he may safely indulge in any form of athletics at school; others wish to know whether the condition of the heart will debar their son from entering one of the Services. The young man wonders whether the valvular heart disease for which he was invalided from the army is any bar to his intended marriage, or a life assurance company may desire to know his expectation of life. The anxious wife's first question is will her husband be spared, and he himself soon begins to inquire whether he can look forward to complete recovery, or whether he must needs relinquish all, or only some of, his former activities. To the physician prognosis is also an important problem because the treatment he recom. mends is often based not only upon a correct interpretation of the patient's symptoms and physical signs, but also upon a reasonably accurate forecast of the degree of health to which the patient may be restored.

It rnay be said that prognosis in heart disease is notoriously speculative and uncertain, and it is true that many intercurrent factors may arise and upset our most careful estimate of the patient's future. Nevertheless, there are certain general principles which we recognise as of the atmost value in guiding us to the knowledge that whereas one patient will make a complete recovery and another may look forward to some years of relatively good, though impaired, health, the life of another is fast drawing to a close.

Prognosis is primarily always dependent on accuracy of diagnosis. The precise data furnished by radiograms, the sphygmomanometer, the polygraph, and the electrocardiograph have placed diagnosis on a firm basis, and the co-relation of this knowledge with symptoms and physical signs has now become so wellestablished that in practice we can usually dispense with the electrocardiograph and other elaborate instrumental methods.

\section{Cardiac Affections.}

The prognosis in relation to cardiac affections is practically always more favourable if organic disease of the heart can be excluded. I do not hold with the theory which sought to minimise or to deny the unfavourable effect of organic valvular disease. Now, no one seriously believes that men with organic valvular disease are really first-class lives, or even that they are fit for military service in category $A$. It is true that some men with organic valvular disease are fit for a hard game of football, or for strenuous physical work, but these cases are exceptional. In the course of the

1 A paper read before the Medico-Chirurgical Society of Edinburgh on July 7 th, 1920. acute endocarditis from which the patient suffered some years previously there were probably more focal inflammatory lesions in the myocardium than we suspected, and these must have left some permanent damage to the heart muscle. Consequently a chronic valvular lesion, apart from the mechanical disability it imposes upon the heart, thereby lowering its reserve force, is often associated with at least some degree of chronic myocarditis.

The prognosis, however, should never be founded solely on a study of the heart. We have to take into consideration the patient's age, sex, and occupation, the state of the arterial walls, the blood pressure, the efficiency of the kidneys, and the state of the pulmonary and other systems. Moreover, we have to remember that chronic degenerative changes due to spirochretal infection are slowly progressive, this being of particular importance in relation to aortic incompetence; whereas acute rheumatic lesions of the myocardium and endocardium are liable to recur, especially if the primary source of infection, whether it be in the tonsils or elsewhere, cannot be located and removed. Even after all the available data have been elicited and weighed we are reminded of the fact that no two cases are exactly comparable, and that each individual case must be judget on its merits.

I do not propose to enter upon the consideration of the phenomena associated with the patient's response to physical exertion, though this is of the greatest value in determining the functional state of the heart muscle, and consequently in ascertaining, for example, whether there is some degree of cardiac failure in addition to valvular disease. Nor shall I consider the symptoms and signs which collectively indicate pronounced cardiac failure, nor the prognostic significance of deficient renal activity in heart disease; but I shall limit my remarks to certain of the more common cardiac disorders which we encounter in the course of our daily work.

\section{Dilatation of the Heart}

Let us first consider the prognosis in dilatation of the heart. I shall not deal with the dilatation which follows as a late and often terminal result of myocarditis, with or without valvular disease, but wish to speak of the cardiac dilatation which apparently ensues as a direct result of some unusual physical stress, or which is first recognised during, or in the early phase of convalescence from, an acute infective illness.

In regard to the former group of cases-namely, those usually spoken of as cardiac overstrain-it may safely be affirmed that physical exertion never causes a pathological degree of dilatation in a perfectly healthy heart. The recognition of this fact renders it difficult, or impossible, to give a wholly favourable prognosis to a patient suffering from cardiac overstrain, although the immediate prognosis may be good. The patient has usually attained an age which makes it almost certain that arterio-sclerosis has already begun, and we remember that age is a matter of tissue change, not merely of years.

The case of a joiner, aged 52 , affords a good illustration. He was employed in a colliery, and enjoyed excellent health until he volunteered for the unaccustomed work of firing boilers during a miners' strike. Ten months later he was still breathless and fit for little work; the heart was preserving its normal rhythm, there was no dropsy, and no murmurs were audible, but the blood-pressure readings were high, the diastolic pressure being 85 and the systolie pressure 170, and after slight exertion the pulse-rate took four minutes to decline to its pre-exertion rate of 90 In such cases of cardiac overstrain the patient must be content to live on a lower plane of activity than formerly. He must avoid calling upon the heart, the reserve force of which is lowered, for more work than it can successfully undertake, and any physical effort which occasions dyspncea, pain, or præcordial distress is harmful. The best advice to give to most of these patients is that which I learned from Cowan, of Glasgow-namely, that an active or a merry life will mean a short one.

In cases of cardiac dilatation from acute infective disease the chief difficulty centres in the question of 
diagnosis. The patient has passed through an acute febrile illness, often of rheumatic or influenzal nature, the heart has become slightly enlarged, the pulse-rate remains somewhat too frequent, and a systolic murrrur has become audible. Has one of the valves been damaged by endocarditis or is the heart merely dilated? It is principally when the systolic murmur is maximal at the cardiac apex that we have to consider the possibility of its being an indication of recent endocarditis which, even although the immediate prognosis be favourable, will leave the mitral valve permanently damaged and will probably cause grave incapacity in the course of years. My own experience has taught me that an apical systolic murmur is almost certainly due, not to organic mitral incompetence, but to dilatation if the apex-beat is not displaced and not unduly forcible, if the murmur is soft in quality and confined to the apical region, if the intensity of the murmur varies notably with change of posture, and if the pulse retains its physiological respiratory irregularity. The conclusion thus arrived at is strengthened if the patient is anæmic, and if there is a functional systolic murmur at the pulmonary, and possibly also at the tricuspid, area.

In these cases of cardiac dilatation the prospect of complete recovery is good. The murmur may persist for weeks or months, but ultimately disappears entirely. It is now a frequent experience to find the heart perfectly normal in men who one, two, or three years ago were invalided out of the army because they presented a mitral systolic murmur which had led to a diagnosis of V.D.H. We are now observing on a vast scale the phenomena to which George Balfour drew attention in his classic observations on "curable mitral disease."

\section{Disorderly Action of the Heart.}

Passing to another common disorder, D.A.H., we recognise this as a symptom-complex, protean in origin, and by no means confined to those who have served in the army. When the man who was always a weakling, unfit to play games at school, and who found his true level in a quiet, sedentary, unambitious walk of life attempts to undertake larger responsibilities, he becomes incapacitated by the giddiness, fatigue, palpitation, præcordial pain, and other symptoms characterising this disorder. We all recognise that this type of person will never become robust. Those in whom the disorder has arisen as a sequel to shell concussion, or in civil life to some other form of trauma, may be expected to improve slowly if under judicious treatment.

After excluding these cases, and those in whom we find visceroptosis, obesity, arterio-sclerosis, early pulmonary tuberculosis, hyperthyroidism, and so forth, we find that in over 40 per cent. of all patients who are said to suffer from D.A.H. there is evidence of some recent infection, and in an additional 10 per cent. there is anæmia, presumably of toxic origin. In all these cases - 50 per cent. of the total-the prognosis is, in my opinion, good. The disturbance may be essentially one of the endocrine glands or of the autonomic nervous system, but it is not the heart that is primarily at fault. If we give a guarded prognosis, keep the patient confined to bed, permit the attention of devoted relations, administer digitalis (which is of no value to the patient), and exercise an anxious watchful supervision lest the patient overtax the heart, we confirm the patient in the belief that he is suffering from serious heart disease, and the condition progresses from bad to worse.

A good prognosis is the first essential in restoring the patient's confidence. He must be told he is not suffering from heart disease, that the heart is healthy, and that he will make a complete recovery. He should not be allowed to lie in bed; the less he is waited on and the more he does for himself the better, for the more he accomplishes the greater the degree of self-confidence he regains. During the first few days massage and passive exercises are of value. When he first begins to walk about his tolerance of exercise is naturally poor, but he should be encouraged to undertake an increas ing amount of physical exercise daily. Within a few days he should be performing active physical exercises under skilled supervision; he is then encouraged to take active exercise out of doors. Drugs are seldom indicated; digitalis is wholly useless.

This method of treatment seldom fails, and is usually speedily and eminently successful in restoring the patient to health. It was so in the army. Of nearly 2000 men under my supervision, 69 per cent. became fit for full duty in the front line; and in 1918, when our organisation for physical testing and training had reached its maximum efficiency, no less than 86.9 per cent. of Class A men, admitted to hospital for D.A.H., became fit to rejoin their units. Relapses very seldom occurred.

In civil life the prospects of full recovery are not so uniformly good. The patient does not lead such a healthy life as does a soldier in a command depôt; he is now less amenable to control. Physical training, needing skilled supervision, is costly and not so efficient as it was in the army; there are devoted relatives whose influence is the reverse of helpful; and in certain grades of the community there is the sure expectation that incapacity for work will be compensated by grants from public funds. Nevertheless, brilliant results may be obtained, even under the adverse conditions of civil life, and a man or woman who has been practically bedridden for months may, within a few weeks, be leading an active and useful life. The cases in whom the dominant manifestations are those of neurasthenia are the most intractable and the most prone to relapse.

Extrasystoles.

Passing to the most common of all forms of cardiac irregularity-namely, extrasystoles. The prognosis should never be based on the extrasystoles alone, but rather on the underlying cause. If they are due to sympathetic stimulation of the heart under the influence of the emotions, or to obvious toxæmia from tobacco, and if the patients are otherwise healthy a favourable prognosis may unhesitatingly be given. Extrasystoles are likewise not of serious significance if they arise, even without definite cause, in young adults in whom the heart is healthy and in whom there are no signs of cardiac failure. That the immediate prognosis in these cases is good is demonstrated by the fact that of 34 soldiers sent to the base solely on account of extrasystoles 22 were proved to be fit for category A after a short stay in hospital and in a training centre. In civil life the conditions are equally favourable for recovery. I cannot recall a single instance of extrasystoles, arising in a young man or woman whose heart was otherwise normal, being the precursors of more grave heart affections. In illustration I refer to one patient who, at the age of 48 , was suffering from syphilis of the lung, the arteries were healthy, and the heart, save for extrasystoles, was normal. Seven years later he was in rude health. In another, aged 41, extrasystoles were observed during a mild rheumatic attack. He made a complete recovery and enjoyed good health for nine years, when the strain of carrying on his business during the war led to insomnia and other nervous symptoms, and in the course of examination a slight mitral leak was detected.

In patients over 40 years of age, however, extrasystoles arising without obvious cause should be regarded with some suspicion, for they probably indicate commencing sclerosis of the coronary arteries. The extrasystoles are the first danger signals, and the man's expectation of life is not first class, although it may be several years before any further manifestations of arterio-sclerosis can be elicited. In these cases the determination of the blood pressure is of particular value, for we know that arterio-sclerosis is often the direct sequel to high blood pressure. In cases with any symptoms of cardiac failure a most careful examination of the pulse should be made in order to ascertain whether there is any alternation of the pulse after the extrasystoles. Even transient alternation, with alternate weak and strong beats, is always of evil omen, and I am in accord with those who find that these patients seldom survive for more than one, or at most two, years. In the aged extrasystoles are not only frequent, but are usually attended with remarkably few symptoms and with a relatively good prognosis. 
Extrasystoles arising in the ventricles are, on the whole, attended with a better prognosis than those arising in the supra-ventricular portions of the heartnamely, auricular and nodal extrasystoles. Whereas a man with ventricular extrasystoles and thickened arteries may continue at his work for some years before becoming seriously incapacitated, the heart of an individual with auricular or nodal extrasystoles has been failing before they were observed.

The isolated, or single, extrasystole is of lesser significance than multiple extrasystoles occurring in series and causing momentary attacks of palpitation or of tremor cordis, because multiple extrasystoles are not infrequently the forerunners of paroxysmal nodal tachycardia, of flutter, or of fibrillation.

$$
\text { Auricular Fibrillation. }
$$

Lastly, as to the prognosis of auricular fibrillation. When this begins we know that the last act has begun. How long will it be before the curtain finally falls? It may be within a few weeks or it may be ten or more years. The prognosis is generally more favourable in those with mitral disease than in those with arteriosclerosis and myocardial degeneration. Apart from this there are four great factors which influence the prognosis: (1) Those without much acceleration of the ventricular rate suffer least and survive longest, whereas a high ventricular rate is unfavourable. (2) The response of the heart to digitalis. Those in whom the ventricular rate is readily controlled by this drug or by strophanthus may for years lead quiet lives with little discomfort. (3). Those in whom the ventricles do not become dilated remain comparatively well, whereas in those who develop dropsy the prognosis is much more grave. The first attack of dropsy is seldom fatal, but it recurs from time to time, and on each occasion recovery becomes more tedious. (4) Finally, we may observe symptoms and signs of chronic nephritis; the cardiac patient has become a cardio-renal one, and we know the fatal issue is within measurable distance.

\section{EFFECTS OF \\ HOT AND COLD APPLICATIONS ON THE SUPERFICIAL AND DEEP TEMPERATURES.}

BY J. J. R. MACLEOD, M.B., CH.B., D.P.H., F.R.S.C., PROFESSOR OF PHYSIOLOGY, DNIVERSITY OF TORONTO;

A. R. SELF, M.A.,

RESEARCH ASSISTANT TO THE RESEARCH COMIITTEE OF THE DEPARTMENT OF MILITIA AND DEFENCE OF CANADA; AND

N. B. TAYLOR, M.B., CH.B.,

CAPTAIN, C.A.M.C.

(From the Laboratory of Physiology, University of Toronto.)

THAT the local application of heat or cold to the surface of the body is of value in the treatment of a variety of clinical conditions is well known, but no data apparently exist to show the extent to which the application causes actual change in the temperature of the underlying tissues. With the aid of the Research Committee of the Medical Services of the Department of Militia and Defence of Canada we have undertaken to carry out a series of observations to collect such data, and the interesting and definite character of the results has prompted us to offer a brief account of them at the present time.

\section{The Apparatus.}

The observations have been conducted on rabbits. Heat or cold was applied over an area of shaved or closely clipped skin by means of an appliance which we have styled the " applicator." For heat two types of these have been used-either an electric pad $(9 \cdot 5 \mathrm{~cm}$.), giving with 0.6 amps., temperatures ranging up to $55^{\circ} \mathrm{C}$. or a water applicator, consisting of a glass tube of $20 \mathrm{~mm}$. internal diameter, closed at one end by a thin rubber membrane and having water from a heatinsulated reservoir circulating through it at a definite and constant temperature.
The exact temperatures at the point of contact of the applicators with the skin was recorded from time to time during the observations by means of thermoelectric couples placed either in the cloth covering the electric pad or just inside the rubber membrane of the water applicator. To measure the temperatures of the tissues thermo-electric couples mounted within hypodermic needles were used. The couples were made of copper constantin wires, the ends being twisted together, and the junction coated with shellac. The sharp ends of the hypodermic needles were sealed with a little solder, so that the couple, occupying about $4 \mathrm{~mm}$. of the needle, lay as near as possible to its point.

The position of the thermo junction in the tissues was determined by measurement of the depth to which the needle was inserted into the tissues, and the angle which it made with the surface. The couples were connected with an Ayrton-Mather dead beat galvanometer, and with a Leeds and Nothrup precision potentiometer, giving direct readings down to $1 \mu \mathrm{V}$. Since the above couples have a thermo-electric force of $40 \mu \mathrm{V}$. per degree C., this means that differences of $\frac{1}{4}^{\circ} \mathrm{C}$. could be measured with precision. The couples were calibrated by placing the hot junctions (in the hypodermic needles) in a bath of warm water with a stirrer and noting the temperature differences corresponding to given E.M.F.'s. The cold junction was placed close to the bulb of a sensitive certified mercury thermometer in water near room temperature in a large Dewar flask. From the results a calibration curve was constructed. The above method has been adopted after trial of several others, and we are greatly indebted to Professor E. F. Burton, of the Physics Department of Toronto University, for his valuable assistance in this part of the work.

\section{Observations of Normal Temperatures.}

A series of preliminary observations of the normal temperatures in the muscles and rectum were made, both before and during the application of local heat at a point of the body far removed from the the thermo couple; Table $\mathrm{I}$. gives the results.

TABLE I.

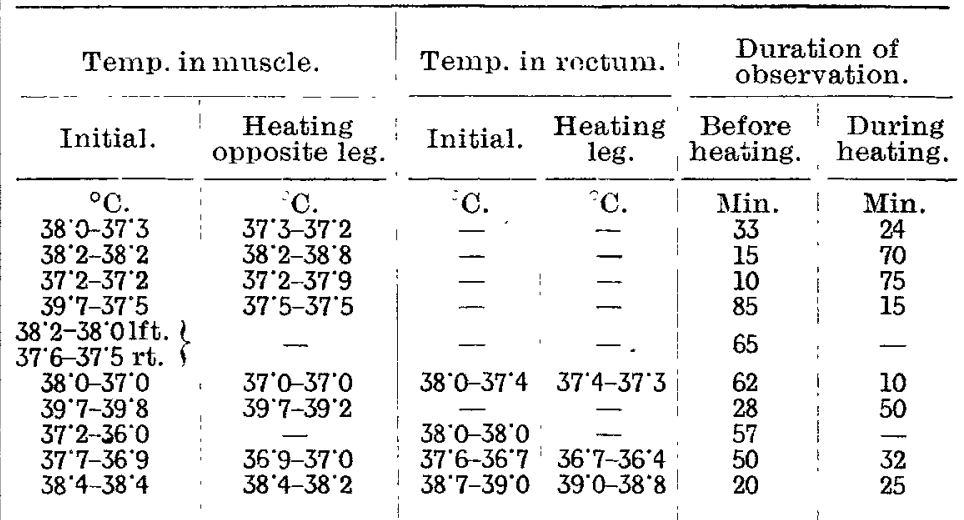

Note.-These figures being taken from curves the second decimal is omitted.

The initial temperatures, it will be seen, varied in the rectum between $36.7^{\circ}$ and $39^{\circ} \mathrm{C}$. with an average of $37^{\circ} 92^{\circ} \mathrm{C}$., and those in muscles between $36^{\circ} 9^{\circ}$ and $39 \cdot 7^{\circ}$, with an average of $3790^{\circ} \mathrm{C}$. Usually, the rectal temperature was a fraction of a degree above that in muscle, and the average deep temperature was somewhat above the normal usually given for rabbits. This difference is of no significance in the present investigation, the important point being that the deep temperature, as measured in the rectum or in muscle, did not change much over considerable periods of time and was not affected by the local application of heat to the surface of the body at some distance from the thermo couple, even when the temperature in the applicator was $15^{\circ} \mathrm{C}$. above that of the skin.

The normal temperature under the skin varied according to whether the fur was clipped closely with the scissors or was completely shaved off. With out removal of the fur, in 13 observations on different days the skin temperatures varied between $36^{\circ} 9^{\circ}$ and $39^{\circ} \mathrm{C}$, the average being $37.94^{\circ} \mathrm{C}$, or practically the 